\title{
ARENDT E A CRISE DA EDUCAÇÃO COMO CRISE DO TEMPO HISTÓRICO
}

Rodrigo Ribeiro Alves Neto ${ }^{(*)}$

\section{A DINÂMICA TEMPORAL DA AUTORIDADE E DA EDUCAÇÃO:}

O termo "autoridade" denomina um fenômeno político repleto de confusões que obscurecem o seu sentido e o seu alcance. Arendt diagnosticou o totalitarismo como uma "tempestade de areia" no meio do deserto do mundo moderno, ou seja, uma tempestade que ameaçou "devastar o mundo que conhecemos - um mundo que, em toda parte, parece ter chegado ao fim - antes que um novo começo, surgindo desse fim, tenha tido tempo de se firmar" (ARENDT, 2004, p. 531). Esse "mundo que conhecemos" e que Arendt afirma "ter chegado ao fim" é o mundo ocidental-europeu sustentado pela tríade tradição, religião e autoridade. O totalitarismo seria, em muitos aspectos, uma resposta destrutiva e suicida para essa perplexidade que iluminou o esgotamento das bases da convivência humana que marcaram a civilização europeia. O desafio do homem moderno consiste precisamente em ter que viver em um mundo comum que já não depende de autoridade, religião e tradição para ser construído, conservado e compreendido. Arendt se distancia tanto da posição conservadora e sua concepção de crise da autoridade como "decadência", buscando a "reafirmação de antigas verdades" e a restauração das autoridades tradicionais ${ }^{1}$, quanto da posição liberal que, em face da crise, reafirma o progresso e rejeita qualquer restrição à liberdade.

Ancorada no passado e mantendo a continuidade da esfera pública com suas fundações e instituições, a autoridade é o que confere fundamento e durabilidade ao mundo comum, garantindo aos recém-chegados por nascimento um mundo pré-estabelecido e estável no qual nascem como estrangeiros. Em perspectiva histórica, a perda da autoridade foi a consequência política ou o derradeiro estágio de um processo de secularização que envolveu a derrocada da trindade romana que, por milhares de anos, uniu religião, autoridade e tradição, esfacelando o fio condutor fornecido

\footnotetext{
${ }^{(*)}$ Professor do Departamento de Filosofia da UNIRIO e do PPGFIL da UFRN.

Orcid: https://orcid.org/0000-0003-2834-5265 . E-mail: rodrigo.alvesneto@ gmail.com.

${ }^{1}$ Arendt a mera restauração da antiga tríade composta pela religião, pela tradição e pela autoridade, pois a autora não diagnosticava a crise do mundo moderno como expressão de uma crise religiosa. A separação entre religião e política e perda da sanção religiosa do âmbito político foi vista por Arendt como vantajosa em diversos aspectos tanto para a religião quanto para a política, ressaltando que todas as tentativas de utilizar a religião para fins políticos conseguem apenas perverter a religião em ideologia. Não sendo o totalitarismo mera implicação política do ateísmo moderno ou uma expressão da morte de Deus, de nada adianta apelar à religião como antídoto contra o mal totalitário. Reafirmar "antigas verdades" e apelar ao fundamentalismo religioso apenas retarda e obstaculiza o desdobramento inevitável dessa crise de natureza política.
} 
pelas significações e pelos parâmetros transcendentes que haviam assegurado a crença em um começo sagrado e a sanção religiosa das instituições público-políticas. O enfraquecimento de todas as formas de autoridade no presente foi iniciado com o Renascimento e com a moderna secularização, tendo se aprofundado com as filosofias do progresso histórico, que substituíram a teleologia escatológica cristã a partir dos séculos XVIII e XIX. O moderno declínio da autoridade está enraizado no enfraquecimento da noção de "fundação política", isto é, uma fonte de estabilidade e legitimidade amparada no cuidado para com a durabilidade do mundo comum, sua memória cultural, suas leis e instituições.

Não são apenas pessoas que encarnam relações de autoridade no mundo, mas também instituições, leis e tradições culturais que dão suporte, significado e moldura ao próprio mundo humano. Mas, para além de toda dimensão hierárquica e assimétrica das relações de autoridade, o que mais caracteriza a autoridade é o reconhecimento daquele que obedece, promovendo uma “obediência voluntária”. Embora efetue certa restrição à liberdade, a autoridade não consiste em um guia diretivo pré-estabelecido para a ação ou alguma submissão involuntária por coerção externa. Por isso, diferentemente da relação de dominação, a relação de autoridade não pode ser nunca exercida ou possuída por alguém, pois é sempre concedida e mantida pelos outros. A noção de autoridade não está ligada ao arbítrio do tirano ou às necessidades inflexíveis da administração doméstica, mas sim a uma prévia fonte pública de legitimidade e reconhecimento que, enraizada no passado, transcende os que exercem poder, estabilizando e legando para o futuro um mundo instituído. A autoridade não utiliza a força ou a persuasão, pois ela é sempre mais que um conselho e menos que uma ordem. A autoridade dos vivos é sempre derivativa, pois o que os romanos nomearam como auctoritas emana sempre do ato instituidor inicial que possui validade porque aumenta a articulação do passado com o presente e o futuro. A autoridade tem suas raízes em uma tradição cultural a ser legada, tornando os jovens herdeiros de um passado a ser reatualizado no que ele tem de vivo e vinculante. Por isso a autoridade é a força de atualização do passado para o futuro, ou seja, a força de vinculação do que vem a ser com o que foi em vista do que ainda será, a força vinculante que funda e principia o sentido da compreensão e da ação. Os jovens ingressam pelo nascimento em um mundo pré-estabelecido com o qual assumem a tensa relação entre as formas instituídas e todo o potencial instituinte da novidade.

Por esta via, a autoridade é o passado vinculante que reúne as sucessivas gerações. A autoridade, assentada sobre o alicerce do passado, confere a permanência e a durabilidade indispensáveis para continuidade do mundo comum. Como sugere o próprio verbo augere (aumentar ou ampliar), do qual deriva o termo auctoritas, a conservação e a memorabilidade 
aumentam, prolongam ou fazem perdurar o mundo comum no seio tempo. A duração pública do mundo está assentada na vinculação entre a autoridade e a iniciativa, o legado do passado e a potencial novidade do futuro. A duração pública reside na capacidade do mundo humano de continuar o que foi iniciado e já é bem como de continuar a iniciar o que ainda não é.

Arendt ressalta que o mundo humano, tanto no todo como em parte, é irrevogavelmente fadado à ruína pelo tempo, por isso ele depende daqueles que assumem a responsabilidade pela sua conservação e pela sua renovação, continuando o que foi iniciado e criando novos inícios. "O mundo, visto que feito por mortais, se desgasta, e, dado que seus habitantes mudam continuamente, corre o risco de tornar-se mortal com eles", afirma Arendt (2007a, p. 243). Em contraste com a natureza, o mundo criado por mãos mortais deve servir de lar não-mortal aos mortais durante o limitado tempo em que eles o habitam. Por isso a autoridade é aquilo que faz com que o mundo preexista ao nosso ingresso nele e continue existindo depois de nossa partida. A autoridade é constituída fundamentalmente pela confiança e pela responsabilidade que cada homem cultiva em relação à continuidade do mundo.

A conservação e a renovação do mundo no tempo interrompem a mera fluidez incessante e irreversível que escoa por uma sucessão sem descanso de "agoras" justapostos, partindo o devir homogêneo, neutro e indiferente em passado e futuro, ou seja, forças temporais heterogêneas que opõem resistência ao mero continuum vazio da eterna mudança sucessiva-linear. Conservação e renovação do mundo impedem que a inserção do homem no presente seja anulada ou devorada pela futilidade do tempo histórico e biográfico. O movimento fugaz da eterna sucessão destruiria incessantemente o "estar presente" do homem, se ele não fosse capaz de conservar e renovar o mundo, isto é, se não fosse capaz de encontrar um espaço de articulação e diferenciação entre o passado e o futuro. A recordação busca salvar os assuntos humanos, as experiências e os eventos históricos da sua futilidade constitutiva e da ruína desértica do devir, pois almeja estabelecer, em relação a eles, uma discussão incessante, da qual nascem certos significados, conceitos e marcos indicadores para a recordação futura. Sem uma tradição cultural que herda, preserva, nomeia, seleciona e transmite as significações, não haveria passado e futuro, restando apenas a sempiterna mudança do mundo e o mero ciclo biológico das gerações que nele vivem

Neste sentido, a autoridade está vinculada à responsabilidade por algo que queremos que perdure e se mantenha digno de recordação futura. Na autoridade está em jogo a capacidade humana de continuar, recordar, reconhecer e preservar o mundo comum, sua moldura institucional e a ordem jurídica que é comum a todos, sem necessidade de coerção e persuasão. De tal modo que o mundo - as diversas fronteiras artificiais, institucionais e culturais que os humanos interpõem entre 
eles e entre si e a própria natureza - mantenha continuidade com suas fundações e suas formas instituídas, manifestando relativa permanência e reconhecimento em face dos sempre cambiantes, frágeis, imprevisíveis e inconstantes negócios humanos. A autoridade concede fundamento e durabilidade para o mundo comum enquanto espaço institucional que transcende o mero ciclo biológico de vida e morte das gerações, tendo em vista garantir a estabilidade para as coisas humanas, sempre em constante mudança. A autoridade articula o passado com o futuro, conferindo transmissibilidade, duração, estabilidade e continuidade entre as gerações. Como diz Myriam Revault d'Allonnes: “A autoridade tem a ver essencialmente com o tempo. Se exerce em um mundo cuja estrutura é temporal. (...) O tempo é a matriz da autoridade” (2008, p. 15). A dinâmica temporal da autoridade se manifesta na capacidade de conservação do mundo, de transmissão, de filiação e, ao mesmo tempo, de responder às crises, descontinuidades e rupturas que rasgam a trama do tecido social. Esse tecido que nenhuma autoridade totalizadora e homogênea será capaz de tramar de uma vez por todas, pois é somente na tensão entre contínuo e descontínuo que ocorre propriamente a duração pública. Porque se trata de um tecido sempre temporal, inscrito na finitude e na historicidade, precisando ser sempre de novo entremeado a cada novo nascimento. É por essa razão que o mundo comum e humano não pode jamais ser entendido como algo pronto, dado e acabado, mas sim algo a de ser continuamente repensado e assumido em função das potenciais renovações e transformações que vêm à luz através dos "estrangeiros" que constantemente chegam a ele. Portanto, existe, para Arendt, compatibilidade entre liberdade e autoridade na esfera da convivência humana. Se autoridade se refere à continuidade (gerere) duradoura do passado, ela depende ainda daqueles que levam a cabo o que esse legado pôs em movimento (agere), assumindo, atualizando e "aumentando" suas decorrências, implicações e transformações futuras.

Porque a autoridade está relacionada com instituir, preservar e transmitir o mundo humano, conferindo passado para o futuro e futuro para o passado, ela é uma dimensão constitutiva da educação. A educação é o âmbito de ligação dos novos com os mais velhos. Educar-se é elaborar quem somos e o que vem a ser na tradição cultural a qual pertencemos, pois o passado, em seu percurso histórico, não apenas nos entrega o que fomos, mas, sobretudo, responsabiliza-nos pelo que nos tornamos. A educação possui uma profunda relevância nessa incessante tarefa de articular passado e futuro; esse desafio humano de conservação e transmissão do mundo aos jovens, apresentando a eles o conjunto de significações, valores, princípios, estruturas científicas, filosóficas, históricas, linguísticas, sociais, econômicas e instituições políticas que constituem o mundo no qual eles vivem. A capacidade dos mais novos de modificar e se apropriar desse mundo quando forem adultos está enraizada na capacidade da educação de assumir a responsabilidade por 
esse mundo e apresentá-lo em toda a sua complexa e multifacetada constituição temporal. A educação se assenta na transmissão, no legado que oferecemos aos recém-chegados ao mundo, na responsabilidade pelo mundo, mesmo que entendamos que ele deveria ser diferente do que é.

Promovendo a mediação dos jovens da esfera privada da família para o mundo público, a educação deve evidenciar aos mais novos que o mundo não é apenas o espaço compartilhado entre aqueles que o habitam no presente transitório, mas que também está relacionado à duração pública, enraizado em um tempo histórico no qual se articulam passado e futuro. Não sendo uma dimensão essencialmente política, a educação cumpre um papel político fundamental ao conceder um passado ao futuro e ao cultivar o futuro do passado, pois, até para poder ser transformado, o mundo comum e humano precisa assegurar a sua conservação, a sua articulação temporal e a relativa continuidade com suas significações e instituições fundantes. A responsabilidade pelo mundo que o processo educacional exige dos mais velhos deve ser compreendida, portanto, como uma forma de assumir a responsabilidade pelo passado, evidenciando aos jovens que não compartilhamos o mundo apenas com nossos contemporâneos, mas também com nossos predecessores e sucessores, com os que nasceram antes deles e com aqueles que ainda nascerão depois. É a capacidade do mundo comum de durar e se transmitir que torna os jovens contemporâneos não apenas de si próprios, mas também contemporâneos do passado e do futuro. A relação educacional está enraizada na autoridade porque exprime a força de vinculação do passado com o futuro no presente. A autoridade, assim compreendida e experimentada, torna possível a permanência e a continuidade de viver juntos entre o passado e o futuro, compartilhando a instituição e a duração do mundo. A instituição de um autêntico mundo comum não está alicerçada apenas em uma pluralidade de homens singulares aptos a ocasionar a novidade, mas também em uma pluralidade de seres mortais que, enquanto tal, constitui uma pluralidade de gerações dependente da continuidade, da estabilidade e da durabilidade da esfera pública.

Porque o mundo é sempre mais velho que aqueles que nele ingressam pelo nascimento, a educação se liga inevitavelmente ao passado, mesmo que a vida transcorra no presente. Para Arendt, a educação está fundada na relação intergeracional, no diálogo entre novos e velhos, ou seja, na relação entre o passado e o futuro. A educação, enraizada no que já é, no passado herdado e na duração mundana, busca transmitir as fronteiras e os canais de comunicação entre os jovens e esse mundo, cuja estabilidade é constantemente ameaçada pelos novos que nele nascem. Cada nascimento é expressão de um novo começo que emerge no mundo, um novo mundo em potencial vem a ser. A educação pressupõe a conservação do mundo, embora ele esteja submetido ao constante movimento de todas as coisas humanas, um movimento que só cessaria se os homens 
deixassem de nascer e morrer. A educação circunscreve cada novo começo e, ao mesmo tempo, assegura a sua liberdade de movimento, a potencialidade da emergência de algo inteiramente novo e imprevisível. A estabilidade do mundo é para a educação o que a memória significa para existência histórica dos homens: o asseguramento da preexistência do mundo comum, da continuidade que transcende a duração individual de cada geração, absorvendo todas as novas origens e delas se alimentando.

Na educação ressoa esse equilíbrio instável ou essa tensão relacional entre a conservação e a renovação do mundo comum e humano. Isso ocorre porque o vir a ser descontínuo da novidade no mundo comum só se torna possível em tensão com a continuidade do que já é. Para trazer o novo à teia de relações humanas pré-existentes é preciso um contexto mundano estável, conservado e garantido por um mundo instituído e preservado. A estabilidade do que "já é” não foi pensada por Arendt a partir do conservadorismo reacionário que repele a novidade e acolhe o mundo tal como é, buscando apenas estagná-lo, resguardando o status quo. O mundo a ser legado, portanto, não deve extinguir ou engessar o espaço da potencial novidade onde a liberdade pode renovar o poder instituidor do mundo comum, manifestando seu caráter espontâneo, imprevisível e ilimitado. Os que zelam pela estabilidade não podem estar fechados para a renovação, a apropriação, a revitalização e, enfim, para o novo que irrompe sobre o mundo a cada geração e a cada vez que o poder conjugado de ação se manifesta na existência pública e ativa dos homens no mundo compartilhado. Existe, portanto, uma tensão constitutiva entre a dimensão agonística da ação, enraizada na aptidão humana para engendrar descontinuidades e inaugurar o novo e a dimensão de estabilidade, manutenção, permanência, conservação ou continuidade do mundo comum. Não pode haver passado sem futuro ou futuro sem passado na duração pública do mundo. Para dizer com Assis César e Duarte:

$\mathrm{O}$ ato de recepcionar ou receber o novo em um mundo já velho não pode se dar sem tensão. Ao mesmo tempo em que a criança e o nascimento representam a salvaguarda da renovação do mundo, o próprio mundo precisa ser também posto a salvo da criança e do jovem. Por isso Arendt argumenta que a educação é sempre indiscutivelmente um campo de tensão, um domínio crítico e em crise (2010, p. 835).

É nesse sentido que a atividade educativa seria como que um convite aos recém-chegados para o pertencimento a um mundo que, para recebê-los, precisa antecedê-los e que, para não ser levado à ruína, precisa deles para a sua contínua renovação, permitindo que esses estrangeiros se tornem capazes de iniciar novas obras e novos feitos e palavras. A cada nascimento, diz Arendt, o futuro está se comprometendo com um novo imprevisível, fazendo com que o curso do mundo seja 
sempre indeterminado e aberto. A educação está situada entre o passado e o futuro porque a presença humana no mundo não é simplesmente dada e entregue pelo funcionamento puramente automático da vida natural que, velada em si mesma e para si mesma, absorve toda a vida individual na vida da espécie. Sem a instituição e a conservação do mundo como morada dos homens haveria somente os ciclos repetidores da vida, ou seja, um movimento homogêneo e automático, desprovido de sentido e finalidade, encerrado em si mesmo na eterna quietude indiferente de uma presença assegurada desde sempre e para sempre. A presença humana no mundo rompe o ciclo repetitivo da natureza instaurando a experiência do tempo, ou seja, a vida humana se move ao longo de uma linha reta em um universo onde tudo se move em movimento cíclico, homogêneo, ininterrupto e repetitivo. Por isso a vida humana carece de dotar suas obras, feitos e palavras de alguma permanência e memorabilidade que impeça o seu perecimento pela ação corrosiva do tempo. Somente assim, conquistando essa "imortalidade" ou essa relativa "imperecibilidade", a memória se tornar um abrigo adequado e estável diante da constante chegada e partida das gerações. Indo sempre em direção à morte, a vida humana arrastaria consigo, inevitavelmente, todas as coisas humanas para a ruína e para a destruição, se não fosse a capacidade de interromper o processo neutro, vazio, contínuo, homogêneo e circular do tempo natural através de feitos, palavras e obras que instauram, preservam e estabilizam o mundo humano. Trata-se de uma tensão ou um combate primordial entre a imortalidade cíclica da natureza (a dzoé, os inflexíveis processos vitais que condicionam o mero viver dos animais, cuja existência prescinde dos homens para ser e se manter sendo o que é) e a mortalidade dos homens (portadores de uma bíos, a "boa vida", uma existência singular realizada em linha reta, na qual vem a ser obras, feitos e palavras formadores de um modo de vida qualificado, imerso em um mundo erigido pelos negócios humanos - pragmatta). Como a durabilidade do mundo humano não está garantida pela mera procriação e pelo movimento circular do tempo natural, os homens precisam fazer surgir aquilo que não existiria por si mesmo e não tem em si mesmo a causa de seu vir a ser. O desafio humano é fazer sobreviver o mundo em que nascemos e morremos como estrangeiros, fazendo perdurar as coisas que nos circundam e em cuja companhia fomos admitidos por curto tempo. Na educação, para Arendt, ressoa de modo privilegiado esse desafio humano ou essa responsabilidade em relação ao mundo comum, pois o processo educativo promove a mediação entre os jovens e o mundo. Como esclarece Arendt:

Se a criança não fosse um recém-chegado nesse mundo humano, porém simplesmente uma criatura viva ainda não concluída, a educação seria apenas uma função da vida e não teria que consistir em nada além da preocupação para com a preservação da vida e do treinamento e na prática do viver que todos os animais assumem em relação a seus filhos (2007a, p. 235). 
Portanto, vemos que é paradoxal a dimensão temporal da educação, uma vez que ela precisa lidar com o pertencimento dos jovens ao mundo mais velho que os precede, mas sem que isso implique em cerceamento do poder de começar algo novo ou exercer a capacidade de renovação dos jovens ao se apropriarem do mundo e rearticularem o tempo histórico. A autoridade resgata e atualiza o passado, responsabilizando-se pelo mundo legado, mas sem determinar de antemão o curso dos eventos futuros. A distinção entre conservação e renovação só pode delimitar diferenças na medida em que demarca algum vínculo diferencial ou uma tensão relacional entre elas.

É o que esclarece Assis César e Duarte:

Justamente porque o mundo está continuamente sujeito à novidade e à instabilidade provocada pela ação dos recém-chegados, assumir responsabilidade pelo mundo aquilo que Arendt denominava de amor mundi - significa contribuir para que o conjunto de instituições políticas e leis que nos foram legados não seja continuamente transformado ou destruído ao sabor das circunstâncias e dos interesses privados e imediatos de alguns poucos. Quem educa não assume responsabilidade apenas pelo "desenvolvimento da criança”, mas também pela própria "continuidade do mundo". Responsabilidade pelo mundo é, portanto, responsabilidade por sua continuação e conservação, aspecto que não se confunde com o conservadorismo tout court, pois Arendt ressalta que somente aquilo que é estável pode sofrer transformação (2010, p. 826).

\section{O FIM DA TRADIÇÃO, A CRISE DO TEMPO E O PRESENTISMO COMO ORDEM TEMPORAL VIGENTE:}

O diagnóstico crítico arendtiano do mundo moderno evidencia que o passado transmitido como tradição perdeu autoridade sobre o presente e o futuro. Se a dinâmica temporal da educação está ligada com a conservação do mundo, ela se encontra atualmente em crise em função da ruptura da tradição e da perda da autoridade, uma vez que tais fenômenos destruíram as certezas e qualquer segurança em nossa relação com o passado. "A crise da autoridade na educação guarda a mais estreita conexão com a crise da tradição, ou seja, com a crise de nossa atitude face ao âmbito do passado", afirma Arendt (2007a, p. 243). Para a pensadora, como diz o aforismo de René Char, "nossa herança nos foi precedida por nenhum testamento". Trata-se de uma ruptura com o elo hermenêutico entre passado, presente e futuro, colocando em risco o acesso aos "tesouros" do passado, obscurecendo nossa capacidade de compreender o presente e elaborar significados para a recordação futura. Encontramo-nos hoje situados na experiência do fim da tradição, cuja cadeia de significações sempre guiou e manteve o espírito pensante vinculado a um aspecto predeterminado 
do passado. A perda dessa cadeia que orientou sucessivas gerações nos vastos domínios do passado implica em um profundo esvaziamento ou uma grande perda de profundidade da existência humana. Para dizer com Arendt:

Não se pode negar que, sem uma tradição firmemente ancorada - e a perda dessa firmeza ocorreu muitos séculos atrás -, toda a dimensão do passado foi também posta em perigo. Estamos ameaçados de esquecimento, e um tal olvido - pondo inteiramente à parte os conteúdos que se poderiam perder - significaria que, humanamente falando, nos teríamos privado de uma dimensão, a dimensão de profundidade na existência humana. Pois memória e profundidade são o mesmo, ou antes, a profundidade não pode ser alcançada pelo homem a não ser pela recordação (2007b, p. 131).

Foi a dissolução da continuidade consciente no tempo, na qual cada geração se fiava em sua compreensão do mundo, que transformou o tempo histórico, desde o último século, em um problema fundamental para o pensamento contemporâneo. Não possuímos mais um passado com autoridade sobre o presente a ponto de fornecer o sentido dos eventos e das experiências atuais para podermos, enfim, tornar significativo aquilo que nos ocorre no mundo, aquilo que fazemos e sofremos, para além da futilidade inerente ao tempo homogêneo, indiferente e vazio da sucessãolinear. A perda da tradição revela que não recebemos o passado por intermédio de uma mentalidade já constituída que herda, questiona, conta, seleciona e confere acabamento à estória resultante do transcurso dos feitos e palavras humanos. Rompeu-se o fio da tradição que promovia o encontro entre o passado e o futuro no presente através de uma sucessão discursiva de significações. Foi rompido o fio que, ligando passado e futuro, instaurava o próprio presente como ponto de continuidade na totalidade do processo histórico. Desconectou-se das circunstâncias atuais e da concretude das experiências vividas a cadeia sucessiva de significações, impedindo que o espírito pensante elabore uma reconciliação consigo mesmo e com o que o homem faz e sofre no mundo. Vivemos em um mundo no qual as bases da nossa tradição política e espiritual não são sequer capazes de formular as questões adequadas e significativas para as nossas circunstâncias.

Quanto menos o passado mantém uma continuidade com o presente, mais o mundo perde profundidade e estabilidade, e mais o homem perde a capacidade de pertencer ao seu próprio tempo. Daí a instabilidade radical e a incessante mutabilidade de nossa época. O pensamento não herda as posses de um passado para um futuro, ele herda um passado em descontinuidade com o presente, tornando o porvir problemático. "Nunca antes nosso futuro foi mais imprevisível”, assevera Arendt (2004, p. 11). Com a perda da autoridade, também o futuro perde força vinculante, pois emerge cada vez mais um tempo sem promessas. Vemos que a dinâmica temporal da autoridade não está 
enraizada apenas na anterioridade do que preexiste no passado, mas também no horizonte de expectativa de um futuro possível que também norteia e organiza a ação e a compreensão. A autoridade, portanto, não está ligada apenas a manutenção de um passado vivo e inesgotável, mas também ao caráter prospectivo de um futuro aberto e não realizado ${ }^{2}$. Por isso afirma Myriam R. d'Allones: "Continuar é continuar começando. (...) O problema fundamental reside em ligar a autoridade e a iniciativa e pôr em evidência que a faculdade dos começos vai ao lado com a autoridade da instituição" (2008, p. 149).

Desprovido de autoridade, o mundo humano se inscreve em um movimento processual ininterrupto, sem começo ou fim, sem autoridade e iniciativa, onde tudo pode mudar a qualquer momento para tornar-se qualquer outra coisa, sem que sejamos capazes de compreender até mesmo o que mudou. Neste sentido, as perdas da tradição, da autoridade e da religião acarretaram a ausência de fundamentos últimos, ou seja, a perda de estabilidade e durabilidade do mundo, cujo ritmo das mudanças e transformações foi intensamente acelerado. Diante dessa crise de estabilidade e perduração do mundo comum, o desafio é como assegurar a "continuidade de uma civilização estabelecida que somente pode ser garantida se os que são recém-chegados por nascimento forem guiados através de um mundo preestabelecido no qual nasceram como estrangeiros" (ARENDT, 2007b, p.128).

Nosso mundo é marcado por uma vertiginosa desfragmentação do tempo, regulado pela exaltação do presente como mobilidade cada vez mais prolongada em seu fluxo transitório, empobrecido de experiência e desprovido de direcionalidade, tornando o porvir opaco e imprevisível, pois o passado nada ensina e o futuro nada realiza. Como diz Byung-Chul Han:

A dispersão temporal não permite a experiência de tipo algum de duração. Não há nada que reja o tempo. A vida não se enquadra numa estrutura ordenada nem se guia por quaisquer coordenadas que engendrem uma duração. Identificamo-nos também com a fugacidade e o efêmero. E, assim, cada um de nós próprios se torna qualquer coisa de radicalmente passageira. A atomização da vida supõe uma atomização da identidade. Cada um passa a ter-se somente a si mesmo, o seu pequeno eu. Em certo

\footnotetext{
${ }^{2}$ Em seu instigante livro Depois do Futuro, Franco Berardi afirma que "O futurismo marcou a sensibilidade e a expectativa do mundo da cultura do século XX. Mas, na última parte do século XX, as premissas filosóficas, estéticas e sociais que desenharam a expectativa de futuro dos modernos se desfizeram, com a dissolução da credibilidade de um modelo progressivo de futuro. (...) O futuro se transforma em ameaça quando a imaginação coletiva se torna incapaz de ver possibilidades alternativas para a devastação, a miséria e a violência. Essa é justamente a situação atual porque a economia se transformou em um sistema de automatismos tecnoeconômicos dos quais a política não consegue escapar. A epidemia de depressão contemporânea se coloca em um contexto de paralisia da vontade, que é um outro modo de dizer precariedade" (2019, p. 135-136)
} 
sentido, sofremos uma perda radical de espaço, de tempo, do ser-com (Mitsein). A pobreza do mundo é uma condição discrônica. (...) Nada perdura além da morte. Hoje em dia, morrer torna-se especialmente difícil. As pessoas envelhecem sem se tornarem maiores (2016, p. 10).

Segundo Arendt, no moderno conceito de história, a perduração ou a imortalidade do mundo no tempo passou a se sustentar não na estabilidade da comunidade política como espaço concreto da liberdade e da rememoração da grandeza dos mortais, mas em um fluxo fluido de desenvolvimento ininterrupto, independente de cidades, Estados e nações, que engloba toda a humanidade. Processos invisíveis passaram a abarcar todos os eventos singulares, causas distintas e específicas, feitos e palavras tangíveis, degradando-os a funções do movimento contínuo de um processo global. Foi assim que o advento das filosofias da história promoveu no homem moderno a convicção de que ele fazia parte integrante de um processo global e interminável, guiado por princípios gerais, tais como “desenvolvimento", "progresso" e "movimento contínuo", que destituem de importância o que quer que tenha vindo antes, dissolvendo qualquer autoridade tradicionalmente consagrada e tornando o passado um mero episódio cujo único propósito seria abolir a si próprio. O processo histórico, então, desconectou-se do mundo comum e humano e se tornou uma interminável cadeia de objetivos, em cujo desenvolvimento ininterrupto os significados de todos os desempenhos passados constantemente se cancelam em função de metas e intenções futuras.

Na medida em que se ampliaram e se aprofundaram os processos de transformação econômica, social, política e cultural decorrentes do aproveitamento industrial da racionalidade técnico-científica, a era moderna promoveu a emergência da "humanidade socializada" e, com ela, a vida da espécie se afirmou amplamente. O processo histórico passou a estar inteiramente centrado no "homem socializado", no homem imerso na esfera socioeconômica, e não mais no "sujeito livre e pensante" ou na vida egoísta do indivíduo liberal, como nos primeiros estágios da modernidade. A esfera pública foi considerada como uma função da sociedade e, progressivamente, a era moderna foi transformando a sociedade no sujeito coletivo desse processo vital de produção e reprodução da vida. A moderna ascensão da esfera do social transformou toda relação política entre os homens em dependência mútua em nome da subsistência. Reduzida à função de suporte do ciclo vital da produção e do consumo, a esfera pública deixa de se constituir pelo envolvimento dos cidadãos mediante atos e palavras, pois a esfera do social substitui a ação pelo comportamento repetitivo e o discurso pela informação coordenada. Passa a imperar a funcionalização, a padronização e o controle das atividades humanas, fazendo surgir uma sociedade de massas supérfluas e desenraizadas, submersas em um gigantesco processo econômico-vitalista no qual os homens se tornam meios ou funções para o funcionamento automático. A 
história como processo passou a representar para os homens o mesmo que a espécie representa para os animais, pois a única coisa que podia ser potencialmente imortal, como o mundo comum na Antiguidade e a vida individual na era cristã, era o próprio processo vital da espécie humana. O avanço da racionalidade instrumental e técnico-científica, na passagem para o século XX, ao invés de exprimir a capacidade do sujeito moderno de mudar, fabricar e intervir na realidade natural e humana, manifestou, na verdade, a destituição subjetiva do homem moderno que sucumbiu na sociedade industrial do mercado, do trabalho e do consumo.

A massificação e socialização do homem instauraram uma dinâmica temporal absorvida pelo ritmo do trabalho que transforma o mundo público e humano em uma "organização pública do processo vital" na qual os interesses privados adquiriram relevância pública. A socialização do trabalho e do consumo instaurou um ritmo temporal no qual passou a funcionar apenas as leis da economia, da inovação técnico-científica e do Estado tecnocrático, formando um sistema fechado em um processo ininterrupto e inflexível. O automatismo do processo vital passa a reger os engajamentos ativos dos homens com o mundo, nutrindo em cada um a crença de que dependemos uns dos outros apenas para garantirmos as tarefas necessárias à reprodução da gigantesca esfera social e econômica. A manutenção da esfera socioeconômica como único ponto de referência dos cuidados humanos com o mundo comum promoveu uma "nova indiferença face a questão da imortalidade" (2007c, p. 109). Tanto a vida individual quanto o mundo comum se tornaram perecíveis, mortais e fúteis. É o que Arendt denomina como "mortalidade absoluta":

Da época moderna até o início de nossa própria era, o mundo moderno, vemos que se passaram séculos antes que nos acostumássemos à noção de mortalidade absoluta, a ponto de não mais nos incomodar a sua ideia e de não mais ser significativo o antigo dilema entre uma vida imortal individual em um mundo mortal e uma vida mortal em um mundo imortal (2007, p. 109)

No mundo moderno, impera a "mortalidade absoluta" em um processo interminável, cujo funcionamento puramente automático absorve a vida individual no movimento global da espécie. O mundo moderno inseriu as massas supérfluas no mero fluxo contínuo de sucessão indiferente de “agoras" descartáveis, predominando somente a afetação constante da fugacidade do presente que, em movimento constante, afunda-nos na sucessão exterior do tempo enquanto mera transitoriedade. O consumo do presente descarta as tensões entre o passado e o futuro a fim de manter vivo a onipresença de um movimento incessante com o qual assumimos uma relação cada vez mais extrínseca (Cf. LEOPOLDO E SILVA, 2008). O presentismo é um ritmo temporal que nos separa 
de nós mesmos, transformando-nos em nossos próprios expectadores impotentes, que olham a fuga contínua de um tempo que escapa e nos falta incessantemente.

Diferentes pensadores contemporâneos diagnosticam o quanto passamos a viver atualmente não apenas um tempo de crise, mas, sobretudo, uma crise do tempo. Trata-se de uma crise da historicidade e da temporalidade, ou seja, uma profunda transformação no regime temporal que nos orienta na vida comum e no pensamento. As transformações que alteram nossa relação com o passado, nossa ideia de futuro e nossa experiência do presente afetam a articulação entre essas dimensões temporais e própria tripartição e do tempo em presente, passado e futuro. Nossa vida comum é fundamentalmente um modo de temporalização e elaboração da história com base em uma tácita ordem do tempo que, por sua vez, articula, a partir do presente, uma diferença temporal entre o passado e o futuro. Não percebemos e experimentamos o tempo histórico da mesma maneira em todas as sociedades, uma vez que o ritmo do tempo não se manifesta como sucessão natural, objetiva, mensurável e exterior, mas como força política e cultural instauradora de diferentes regimes temporais que governam uma época. A noção de "regime de historicidade", introduzida por Marshal Shalins (1987) e elaborada para a História, entre outros, por Marcel Detienne (2001), Koselleck (2006) e Hartog (2014) tem o propósito de considerar uma pluralidade de relações com a temporalidade. O tempo é uma experiência e uma elaboração histórica e cultural, visto que existem diferentes regimes temporais, sobrepostos uns aos outros, e não apenas um tempo histórico único, distinto do tempo natural, quantificável e psicológico. As diversas sociedades e culturas perceberam, vivenciaram e lidaram com o tempo de modos inteiramente distintos. Existem muitas formas de pensar e experimentar a temporalidade, ou seja, o tempo se diz de muitas maneiras. Os modos distintos de ordenar o passado, o presente e o futuro, na medida em que instauram a fisionomia de uma dada época, podem ser um instrumento para comparar tempos históricos diferentes, lançando luz sobre formas singulares de experiência do tempo.

Os "regimes de historicidade" são as formas históricas de articulação entre passado e futuro em determinado presente, ou seja, formas hegemônicas de representação do tempo em determinada sociedade. Na esteira do trabalho de Koselleck, o historiador François Hartog (2014) nos mostra que uma "ordem do tempo" é, simultaneamente, articulação temporal e comando. São "ordens" porque, de tão imperiosas, chegam a nos submeter sem que as percebamos imediatamente. De tal modo que, para contradizer uma "ordem do tempo", precisamos entrar em choque com ela. O passado não é, portanto, algo objetivo, mas sim construído a partir de problematizações geradas em uma determinada atualidade. E o futuro não é algo dado, pois constantemente ressignificado em cada presente. Desse modo, o tempo é uma categoria central na constituição de nossa vida comum e 
a representação cultural do tempo domina a experiência vivida em todas as suas expressões. Embora sempre contestada, uma ordem do tempo se instaura lentamente e pode durar longamente.

Por esta via, o passado, o presente e o futuro podem assumir relações bem distintas entre si, formando o "tempo histórico" ou o regime temporal de uma época determinada. Existem contextos históricos nos quais a temporalidade é experimentada como o que se desenrola pausadamente. Em outras situações, o tempo parece estar acelerado, em função da rapidez das transformações políticas ou tecnológicas. E existem períodos atravessados por movimentos revolucionários, nos quais há a sensação de que o futuro é aqui agora, encontrando-se fundido ao presente. Em outras épocas, o futuro parece permanecer "atrelado ao passado", tal como naqueles em que as expectativas do futuro não se referem a este mundo, mas sim a um outro que será escatologicamente trazido pela redenção dos tempos. Hartog (2014) examina de que modo os ritmos temporais emergem dos diferentes modos de articulação entre passado, presente e futuro. Caso a ênfase seja colocada no passado, no futuro ou no presente, a ordem do tempo sofrerá variações. Quanto menor a diferença temporal do presente em relação ao passado, mais encurtado será o horizonte de expectativas, como nas sociedades tradicionais. Quanto menor a articulação temporal do campo de experiência com o presente, mais ampla será a abertura para o futuro, como na sociedade moderna.

Diversos autores consideram que se tornou cada vez mais predominante em nossa atual experiência do tempo a categoria do "presente", da qual emerge, de modo inédito, o "presentismo" como forma contemporânea da temporalidade. Trata-se de um regime de historicidade, cuja maior implicação é a desistoricização da existência histórica e uma destemporalização do tempo. Nossa relação com a temporalidade estaria marcada, portanto, pelo apagamento de todo horizonte de espera e pela paralisação ou estagnação do tempo histórico mediante uma mobilização contínua do atual em velocidade onipresente. Vivemos como se cada dia fosse o último, pois, como diz uma conhecida propaganda de cartão de crédito: “a vida é agora”. Parte-se do presente, mas para retornar a ele, pois nada escapa de sua sincronia. A temporalidade do existir contemporâneo institui um tempo que se exprime sob a forma de um presente interminável no qual nos tornamos cada vez mais incapazes de rememorar o passado e imaginar o futuro, uma vez que, aderindo imediatamente à onipresença de um movimento incessante, o homem deseja ser flexível em face das incertezas e riscos de um presente múltiplo, multidirecional, sem densidade e espessura. Um presente tão vazio que se exprime na ansiedade incessante de "preencher o tempo" por um ativismo avassalador que deseja sempre cada vez mais desempenho e performance em menos tempo. Passa a imperar a contração do tempo e a dilatação do presente em uma velocidade que consome cada instante em seu caráter imediato. 
Vivemos em uma sociedade presentista que cultua a atualidade em seu fluxo ininterrupto de novidades transitórias e curiosidades relativas. Não se experimenta nessa consagração do presente nem o passado, nem o futuro enquanto autênticas forças temporais, somente a afetação constante da fugacidade do "agora", que nos afunda na sucessão exterior do tempo enquanto mera transitoriedade. A noção de atualidade aqui recusa todo campo de experiência e todo horizonte de expectativas, pois se comprime na perspectiva estreita do "aqui e agora", do dado pontual do instante na sua mais efêmera imediatidade.

Ficamos hoje perplexos com o fato da extrema variação e velocidade do "progresso" promoverem indiferença, previsibilidade, rotina e ausência de significado. Trata-se de um enfraquecimento da capacidade de apreendermos inteiramente os significados das mudanças, resignando-nos a tomar esse fluxo acelerado como um fim em si mesmo, como se fossemos não protagonistas ou agentes das mudanças, mas sim meros passageiros alheios e despreocupados com o devir histórico. A consequência dessa ruptura entre o campo das experiências e o horizonte das expectativas é certo empobrecimento existencial e histórico que nos faz valorizar o efêmero, o descartável, o trânsito do presente, aprofundando a banalização da experiência. Um mundo ligado ao trânsito efêmero do tempo de que passa tende a substituir freneticamente o novo pelo mais novo, tornando a própria mudança corriqueira e correndo o risco de se esquecer totalmente até do que mudou, uma vez que neutraliza o poder historicamente transformador de tudo que é novo, fortalecendo, na verdade, a manutenção do já existente. O presentismo é o nome para uma temporalização que resulta da evaporação de toda espessura temporal e da instauração de uma velocidade instantânea e fosforescente que enfraquece a articulação entre o passado e o futuro. Trata-se de uma ordem do tempo na qual o presente se encontra cada vez mais prolongado, desconectado do passado, pobre em experiência e com o futuro cada vez mais obscurecido, esvaziado, opaco e neutralizado. Como diz Arnold Gehlen, autor que introduziu o termo "posthistorie" na discussão sobre a contemporaneidade, o progresso foi transformado em rotina nas sociedades atuais. Em sua obra Fim da Modernidade, Vattimo explicita o sentido desse diagnóstico:

As capacidades humanas de dispor tecnicamente da natureza se intensificaram, e continuam intensificando-se, a tal ponto que, enquanto novos resultados sempre se tornarão alcançáveis, a capacidade de disposição e de planejamento os tornará cada vez menos "novos". Já agora, na sociedade de consumo, a contínua renovação (das roupas, dos utensílios, dos edifícios) é fisiologicamente requerida para a pura e simples sobrevivência do sistema; a novidade nada tem de "revolucionário" e perturbador, ela é o que permite que as coisas prossigam do mesmo modo. Há uma espécie de "imobilidade" de fundo do mundo técnico (...). O progresso se também se 
torna rotina porque, no plano teórico, o desenvolvimento da técnica foi preparado e acompanhado pela "secularização" da própria noção de progresso: a história das ideias levou, através do progresso que também pode ser descrito como o desenvolvimento lógico de um raciocínio, ao esvaziamento dessa noção. A história que, na visão cristã, se apresentava como história da salvação tornou-se, primeiramente, busca de uma condição de perfeição intramundana e, depois, progressivamente, história do progresso. Mas o ideal do progresso é vazio, seu valor final é o de realizar condições em que sempre seja possível um novo progresso. Suprimindo, porém, o "para onde", a secularização se torna também dissolução da própria noção de progresso precisamente aquela que sucede na cultura entre os séculos XIX e XX. (...) A história contemporânea não é apenas a que diz respeito aos anos cronologicamente mais próximos de nós; ela é, em termos mais rigorosos, a história da época em que tudo, mediante o uso dos novos meios de comunicação, principalmente a televisão, tende a nivelar-se no plano da contemporaneidade e da simultaneidade, produzindo também, assim, uma des-historicização da experiência (1996, p. XII. XIII, XIV).

O presentismo se estabeleceu, portanto, desde o fim da segunda guerra mundial, com o declínio do futurismo utópico iluminista, o desmantelamento da supremacia metafísica do sujeito racional emancipado como fundamento do conhecimento e da ação, a avalanche das inovações técnico-científicas, a intensa aceleração do tempo, o predomínio da velocidade instantânea, a expansão planetária da racionalidade instrumental capitalista, o agigantamento das forças produtivas e o consumo desenfreado, a substituição da política pela gestão tecnocrática da massificação e da globalização econômica, a desrealização do tempo e do espaço, a midiatização e a espetacularização dos eventos, a transformação do progresso em rotina, a destruição da experiência e a anulação da expectativa, dentre outras transformações que promoveram uma mutação no modo pelo qual passado e futuro são postos em relação na modernidade tardia, obscurecendo a localização dos homens no devir histórico.

François Hartog (2014) considera que a ordem do tempo se tornou presentista com a ascensão do consumo, a aceleração da mudança, a moda e os estilos efêmeros, a publicidade agressiva e uma cultura midiática planetária. Nesse contexto, esvaneceu-se o sentido histórico, não há mais emulação de um passado consagrado ou as promessas emancipatórias do futuro utópico. O futuro se torna opaco e até ameaçador, ao passo que o passado é esquecido ou compulsivamente visitado, arquivado e conservado como patrimônio cultural e museal. O presentismo abole a diferença e articulação entre experiência e expectativa porque instaura uma sempiterna mudança em movimento incessante na qual nada pode ter lugar ou durar tempo suficiente para fazer parte do 
mundo. Esse "presente monstro" (HARTOG, 2014, p. 259) se torna um regime temporal único porque não é determinado por coisas que não são mais e por coisas que não são ainda, mas apenas por si próprio em movimento constante. Hartog afirma que o presente se torna, simultaneamente, tudo, uma vez que fora do presente em movimento não há nada; mas ele é também quase nada, visto que está condenado a deixar de ser pela "tirania do imediato" que o consome continuamente. Trata-se de uma mobilização intransitiva que nos confina na sucessão veloz de instantes pontuais em fuga contínua e incessante, ou seja, a movimentação imóvel de um tempo estagnado e autorreferente. A hiperatividade, a variação e a velocidade do presente onipresente ou da onipresença do movimento promovem indiferença, tédio, monotonia, apatia, cansaço, o stress como modo de vida, depressão ${ }^{3}$, exaustão, ansiedade, rotina e ausência de significado.

Nas palavras de Hartog:

Nessa progressiva invasão do horizonte por um presente cada vez mais inchado, hipertrofiado, é bem claro que o papel motriz foi desempenhado pelo desenvolvimento rápido e pelas exigências cada vez maiores de uma sociedade de consumo, na qual as inovações tecnológicas e a busca de benefícios cada vez mais rápidos tornam obsoletos as coisas e os homens, cada vez mais depressa. Produtividade, flexibilidade, mobilidade tornam-se as palavras-chave dos novos administradores. Se o tempo é, há muito, uma mercadoria, o consumo atual valoriza o efêmero. A mídia, cujo extraordinário desenvolvimento acompanhou esse movimento que é, em sentido próprio, sua razão de ser, faz a mesma coisa. Na corrida cada vez mais acelerada para ao vivo, ela produz, consome, recicla cada vez mais palavras e imagens e comprime o tempo: um assunto, ou seja, um minuto e meio para trinta anos de história. O turismo é também um poderoso instrumento presentista: o mundo inteiro ao alcance da mão, em um piscar de olhos e em quadricromia. (...) O futurismo deteriorou-se sob o horizonte e o presentismo o substitui. O presente tornou-se o horizonte. Sem futuro e sem passado, ele produz diariamente o passado e o futuro de que sempre precisa, um dia após o outro, e valoriza o imediato. Os sinais dessa atitude não faltaram. Assim, a morte tem sido cada vez mais escamoteada (2014, pp. 147-148).

O predomínio do presente torna o mundo um domínio apenas dos vivos, pois "os mortos" não pesam mais sobre os "ombros dos vivos", uma vez que tudo se passa como se ninguém mais morresse. Impera a recusa do envelhecimento e a valorização crescente da eterna juventude (Cf. HARTOG, 2014, p. 149). A transformação do tempo em mercadoria se aprofundou de tal modo

\footnotetext{
${ }^{3}$ Cf. KEHL, M. R. O tempo e o cão: a atualidade das depressões. São Paulo: Boitempo, 2009 e BYUNG-CHUL HAN. Psicopolítica - o neoliberalismo e as novas técnicas de poder. Belo Horizonte: Âynié, 2018.
} 
que, no tempo do consumo, também o próprio tempo se torna um objeto a ser comprado e consumido. Como diz Guy Debord, "O tempo que tem sua base na produção das mercadorias é ele próprio uma mercadoria consumível" (1997, p. 70). Por um lado, o privatismo e o empreendedorismo mercantilizaram o tempo, mas, por outro, o desemprego, a precarização e os inempregáveis formam uma massa de homens supérfluos, "homens sem futuro". "O desemprego contribui fortemente para o confinamento no presente e para um presentismo, agora penoso e desesperado", afirma Hartog (2014, p. 148). Trata-se de uma experiência do tempo na qual não mais se tem tempo, pois o ativismo apressado confisca o espaço da experiência e o horizonte das expectativas. Trata-se de um tempo acelerado, contraído e vazio que não elabora antecipação e prospecção, pois é desprovido de densidade e qualidade. O tempo pontual plasmado no presente não passa e não promove mudanças, pois, sendo vazio, precisa ser preenchido pelo turbilhão das ocupações.

\section{A CRISE DA AUTORIDADE E DA EDUCAÇÃO COMO CRISE DA TEMPORALIDADE HISTÓRICA:}

O presente cada vez mais prolongado, desconectado da tradição, pobre em experiência, desprovido de direcionalidade e com o futuro cada vez mais opaco e ameaçador é repleto de profundas implicações para a educação. De tal modo que a crise da educação, diagnosticada por Arendt, está enraizada em uma crise do tempo histórico que afeta nossa atualidade. A crise da autoridade e da educação, tal como diagnosticadas por Arendt, são expressões da crise da temporalidade e da historicidade no mundo moderno.

Nossas análises precedentes explicitaram de que modo a educação está situada na recíproca relação entre passado e futuro, continuidade e ruptura, conservação e renovação. Para preservar a novidade, a educação precisa se orientar na herança, no legado do passado e não pretender orientar as ações dos herdeiros no futuro, como se pudesse produzir e controlar a novidade. A educação não pode ser a salvação do presente para um futuro pré-moldado. Os recém-chegados ao mundo nos confere essa autoridade de representante de um mundo que já se encontrava aí e é, portanto, mais velho. É intransferível essa responsabilidade dos adultos pelo mundo, pois a substituição da autoridade pela igualdade elimina a diferença entre as gerações. Contudo, a crise da autoridade na educação e a instalação do presentismo exprimem a crescente desresponsabilização dos adultos com relação ao mundo e ao passado. "A autoridade foi rejeitada pelos adultos e isso somente pode significar uma coisa: que os adultos se recusam a assumir a responsabilidade pelo mundo ao qual trouxeram as crianças", diagnostica Arendt (2007a, p. 240). 
Em uma sociedade presentista, a busca incessante por "atualização" possui sempre mais importância e o repertório de competências e saberes técnicos necessários para essa atualização competitiva no mercado de trabalho sofre constantes renovações. Por isso cresce a preocupação por parte das escolas em acompanhar esse movimento de inovação tecnocientífica. E, desse modo, o mundo comum e as coisas humanas se revelam instáveis e fugidios, pois sempre rapidamente obsoletos e desatualizados. Por isso dizia Octavio Paz que "nunca se envelheceu tanto e tão rápido como agora". Os professores perdem cada vez mais o papel de quem apresenta aos novos o mundo que existia antes deles, transformando-se muitas vezes em auxiliares dos jovens na corrida pela atualização constante. A educação, perdendo elo com um passado herdado, fica dirigida para um futuro obscuro e imediato e, seja qual for a sua contribuição, seu trabalho sempre será insuficiente ante as novas demandas de atualização. Para dizer com Assis César e Duarte:

Para Arendt, vivemos numa "sociedade de massas" que prioriza as atividades do trabalho e do consumo; que deseja avidamente a novidade pela novidade, (...) que nada quer conservar do passado, consumando-se aí a perda da autoridade e da tradição. Para a autora, vivemos num mundo em que qualidades como distinção e excelência cederam lugar à homogeneização e à recusa de qualquer hierarquia, aspectos que se refletem imediatamente nos projetos educacionais contemporâneos. À primeira vista, estas considerações parecem assumir um caráter elitista, quando não reacionário. Mas não se trata disso. $\mathrm{O}$ aspecto para o qual Arendt chama a atenção em sua reflexão sobre a crise da educação contemporânea diz respeito ao fato de que as fronteiras entre adultos e crianças vêm se tornando cada vez mais tênues, problema que, por sua vez, põe em destaque a falta de responsabilidade e o despreparo dos adultos para introduzir os recém-chegados no mundo. Afinal, como proceder criteriosamente nessa introdução educacional ao mundo quando a velocidade das transformações desse mundo é de tal monta que ele permanece desconhecido e estranho mesmo para os adultos que nele habitam e que, portanto, deveriam conhecêlo? $(2010,826)$

A atual crise da educação é expressão do enfraquecimento da tensão entre novidade e tradição provocada pelo presentismo, pois a consagração do presente abole a articulação entre o passado e o futuro. Absorvido na ordem presentista, o passado vai se transformando em mercadoria para o consumo instantâneo e voraz de adultos e jovens governados pelo ideal da felicidade imediata. O presentismo enfraquece o desafio da educação, isto é, aumentar as fundações do mundo a partir da transmissão da potencialidades inacabadas de um passado vivo, reservatório sempre inesgotável de sentido, sem anular o caráter imprevisível de um futuro aberto e indeterminado.

Nas palavras de Fina Birulés: 
Sabemos que sem uma forma de se relacionar com seu próprio passado, a realidade se torna opaca, ininteligível. Um mundo sem passado nem futuro é um mundo natural, não humano, com um - por assim dizer - presente sempre idêntico a si mesmo. É um espaço em que não sabemos o que significa conservar nem o que significa inovar. (...) Se o final da tradição assinala ao mesmo tempo a dificuldade de conservar e de inovar, o desejo de encontrar caminhos para responsabilizar-se pelo passado significa a vontade expressa de encontrar formas que possibilitem acrescentar algo próprio ao mundo; de criar sentido. (...) A memória - conjuntamente com a expectativa - está relacionada com experimentar o tempo presente e sua heterogeneidade com os outros tempos gramaticais. Um tempo estruturado ou pontuado pela antecipação, pela memória e pela atenção é diferente de um tempo constituído por uma série de instantes que são apenas cortes virtuais na continuidade de uma mudança perpétua. A responsabilidade política é, entre outras coisas, situar-se para além de um presente sempre idêntico, que se pode manter durante algum tempo, mas não rejuvenescer, como observou Ágnes Heller. A responsabilidade liga-se com algo que queremos que perdure, que assumimos do tempo que já não é mais presente e ainda não é futuro (2016. p. 129).

No presentismo, o futuro é olhado a partir de um presente contínuo, sem rupturas entre nós e as gerações futuras. Assim, o passado não orienta mais o presente e não serve de horizonte para imaginar um futuro que, por sua vez, não serve mais de guia para o devir histórico e a localização dos homens no tempo. Trata-se de certa paralisação ou estagnação do tempo histórico mediante uma mobilização contínua do atual em velocidade onipresente. Parte-se do presente, mas não se sai dele, uma vez que nada escapa de sua sincronia. "Em certo sentido, só há mesmo presente: não infinito, mas indefinido" (HARTOG, p. 258), um presente estendido e interminável. A transmissão e a mediação características da educação ficam profundamente prejudicadas em um mundo no qual o presente é já passado antes mesmo de ter ocorrido completamente. Trata-se de um presente que não participa do passado e do futuro, sendo continuamente inabitável. Nele há muitas ocorrências e nada acontece, pois tudo é presente ao mesmo tempo. Nosso presente fabrica cotidianamente o passado e o futuro de que necessita. Nesse presente dilatado, propaga-se a amnésia e a destruição da experiência, pois o presente em mudança contínua destitui de densidade da experiência, mina a iniciativa e destrói as expectativas. É nesse sentido que afirma Birulés:

Talvez o atual descrédito da cultura e da educação guarde alguma relação com o encolhimento dos intervalos de nossa experiência, pois há muito que a categoria do presente se tornou o único horizonte possível e dominante, canibalizando tanto o 
passado quanto o futuro. Com isso, toda transformação e toda herança se veem reduzidas a um fenômeno inelutável de força quase natural (2016, p. 133).

Mais que possibilitar um saber e um saber fazer, a educação tem como tarefa primordial contribuir para que os jovens estabeleçam uma relação de sentido e de pertencimento ao mundo sempre mais velho que eles e que conta com eles para não ser levado à ruína. Em uma sociedade presentista, na qual conhecer e fazer ganham cada vez mais importância, na qual o repertório de competências e saberes necessários para a vida cotidiana e para a competição no mercado de trabalho sofre constantes renovações, há uma preocupação crescente no espaço escolar em acompanhar o que se denomina de "progresso científico e tecnológico". Nessa progressão contínua e ininterrupta da inovação, o conhecimento dos mais velhos se tornam rapidamente obsoletos, fazendo com que os jovens avaliem o passado como tendo pouco a oferecer em um mundo em constante movimento. Os professores já não se assumem mais como representantes do mundo aos novos e já não se sentem em condições de apresentar o universo de cultura e saberes estabelecidos, sendo transformados em auxiliares dos mais jovens na corrida por novos conhecimentos e tecnologias. Nesse quadro, a educação, sem elo com um passado herdado, está dirigida para um futuro desconhecido e, seja qual for a sua contribuição, seu trabalho sempre será insuficiente ante as novas demandas. Ninguém duvida que as ciências e as tecnologias possuem um papel fundamental para a formação dos alunos, mas a educação tem como desafio transmitir a responsabilidade pelo mundo (cf. ALMEIDA, 2011).

Para Matos (2008), a temporalidade aderida à aceleração do presente instaura o "presenteísmo", ou seja, um ritmo temporal que se apodera de todos os espaços democráticos, a começar pela educação

que deixa de ser "educação para a liberdade", tornando-se "educação para a adaptação", substituindo-se a noção de "cultura geral" pela de "cultura comum", cuja finalidade essencial é "preparar os jovens para entrar no mundo tal como ele é". Essa adesão ao presente plano, caso permita algum sonho, este é paradoxal, sonha tão somente com o status quo, deseja que nada de novo venha a abrir o tempo histórico e o futuro. O tempo na contemporaneidade é fatalizado pela ordem das urgências que significa uma oscilação na razão instrumental, o culto dos meios e esquecimento dos fins. Ele é o reino das revoluções tecnológicas do progresso.

A consagração do presente, como diz Lipovetsky (2005), representa a época da cultura hedonista e psicologista na qual emerge o indivíduo cool, flexível e hedonista, desprovido de grandes estruturas de sentido coletivas, que não obedece a normas tradicionais e cultua o trânsito do 
presente. A articulação do passado e do futuro na educação é obstruída pelo presentismo porque ele destrói as grandes estruturas tradicionais de sentido e instaura o ritmo temporal da moda e do consumo. As grandes estruturas socializantes na modernidade perdem autoridade, as grandes ideologias já não estão mais em expansão, os projetos históricos não mobilizam mais - instala-se a "era do vazio".

A crise da educação revela que o passado não serve de referência, tampouco o que ainda está por vir. Só o presente, em seu trânsito homogêneo, tornar-se referência, embora vazia e contingente. Uma sociedade presentista é aquela que transformou a própria crise em trivialidade rotineira, pois recusa a autêntica experiência da crise e das escolhas e mutações que lhes são intrínsecas. Passamos a experimentar a crise e a mudança em regime de relação extrínseca, sem transformação interna e externa. É neste sentido que o próprio Agamben (2013) ressalta o quanto a concepção que temos hoje da mudança e da crise se tornou um instrumento de dominação política:

A concepção atual de crise se refere a um estado duradouro. Assim, essa incerteza é estendida ao futuro, ao infinito. É exatamente o mesmo com o sentido teológico: o Juízo Final era inseparável do fim dos tempos. Hoje, no entanto, o juízo é divorciado da ideia de resolução e repetidamente adiado. Então o prospecto de uma decisão é cada vez menor, e um processo interminável de decisão jamais se conclui. A crise atual tornou-se um instrumento de dominação. Ela serve para legitimar decisões políticas e econômicas que de fato desapropriam cidadãos e os desproveem de qualquer possibilidade de decisão (2013, p. 3).

O paradoxo do presentismo reside no fato de que nunca vivemos tantas mudanças e nunca fomos tão incapazes de mudar, tão incapazes de projetar um mundo, o que implica na anulação da expectativa. Nunca antes o mundo e o tempo histórico foram tão flexíveis, marcados pela variação e pela velocidade de mutações, mas, ao mesmo tempo, nunca antes os homens se sentiram tão incapazes ou impotentes para mudar o mundo e conservar a história que, no entanto, deve a sua existência a eles. Nossa incessante busca por atualidade promove hoje uma evaporação da espessura temporal. As novidades transitórias e as inovações tecnológicas não nos afetam mais como surpresa, antes tende a nos entediar como continuidade rotineira de um processo com o qual já nos acostumamos e que, na medida em que se define pela apresentação do novo, não tem mais nada de novo a nos oferecer. As mudanças deslizam na superfície dos sujeitos e na superfície dos objetos, sem penetração ou profundidade. Preso ao presente, os indivíduos renunciam a participar ativamente das transformações de sua própria história. É o devir histórico sendo vivenciado no regime da exterioridade que anula as possibilidades emancipadoras da crise e impele a todos ao consumo indiferente do que é sempre novo e sempre igual (cf. LEOPOLDO E SILVA, 2008). 
É por esta via que a incapacidade de fazer e transmitir experiência, como indicou Benjamin, não decorre exclusivamente ou necessariamente do emudecimento em face da catástrofe das guerras, pois é suficiente nossa pacata existência cotidiana em uma grande cidade. Como ressalta Agamben, o homem contemporâneo está imerso no cotidiano de uma vida corrente que "não contém quase nada que seja ainda traduzível em experiência. (...) O homem moderno volta para casa à noitinha extenuado por uma mixórdia de eventos - divertidos ou maçantes, banais ou insólitos, agradáveis ou atrozes - entretanto nenhum deles se tornou experiência" (2005, p. 22). A "pobreza da experiência" significa não apenas a carência, mas a sobrecarga e a saturação das vivências que, contudo, não duram no mundo tempo suficiente para serem convertidas em experiência. Por isso a destruição da experiência e a anulação da expectativa são intrínsecas à projeção infinita de movimento ininterrupto e sem direção. Nas palavras de Benjamin, na obra Experiência e pobreza:

Pobreza de experiência: não se deve imaginar que os homens aspirem a novas experiências. Não, eles aspiram a libertar-se de toda experiência, aspiram a um mundo em que possam ostentar tão pura e tão claramente sua pobreza externa e interna, que algo de decente possa resultar disso.

A profusão multicolorida dos eventos cotidianos se revela estéril, pois a impressão de uma abundância de possibilidades parece não enriquecer e elaborar experiências para a recordação futura. Ao experimentar essa velocidade de mutações constantes, observamos o paradoxo de que o acúmulo de mudanças e a multiplicidade dos conteúdos não tornam a nossa experiência mais densa, e sim, pelo contrário, mais fluida e vazia, uma vez que não conseguimos vivenciá-la plenamente. Tudo se passa como se a quantidade de crises e mutações nos impedisse hoje de experimentar a qualidade de um tempo vivido como transformação. Tudo se passa como se não pudéssemos paralisar o tempo ininterrupto de atualização como movimento constante. A crise da autoridade na educação é expressão da predominância de um devir sem o tempo humano, de um tempo sem história, de uma sociedade sem memória, de uma democracia sem política, de uma vida sem liberdade, de um ritmo temporal imobilista no qual tudo se movimenta em uma sucessão contínua e acumulativa sem nenhuma mudança transformadora, neutralizando o que Benjamin chamava de "índice misterioso do passado que o impele à redenção", sufocando a transgressora contingência do porvir e reforçando a necessidade de um presente fechado em si e em constante processo irresistível, exterminador, inconclusivo, inflexível e ininterrupto. A ruptura do presente com o passado enquanto tradição e fonte para a recordação futura ameaça o próprio presente a uma perda de si mesmo, uma perda de peso e gravidade, ao esquecimento de sua historicidade, mantendo-o preso ao mero fluxo transitório. 
Nesses transes e interstícios históricos em que ocorre uma quebra na continuidade do tempo, o desafio educativo de articular e mediar o passado com o futuro se vê inserido em uma profunda crise, pois vê-se diante de um mundo que parece ter chegado ao fim antes que um novo começo tenha surgido desse fim. O perigo dessa crise é sempre a perda do passado junto com a tradição e, assim, a perda da memória que confere significado e profundidade para a existência histórica de seres mortais. Tradição e passado não são a mesma coisa, pois a transmissão operada pela tradição está vinculada apenas a um aspecto predeterminado do passado, fazendo com que o fim da tradição possa sempre abrir o presente para uma nova relação com um passado inacabado e impensado, articulando-o com suas novas potencialidades futuras. O passado nunca se reduz à tradição que o transmite, pois a tradição é também fonte de esquecimento e obscurecimento daquilo que ela exclui e seleciona ao transmitir-se.

Por isso a crise da autoridade na educação, segundo Arendt, poderá nos conceder hoje uma oportunidade à reflexão, caso assumamos a tarefa de repensarmos ao invés de somente pressupormos as categorias usuais fornecidas pela tradição oficial. A reflexão arendtiana nos ensina que a meditação sobre a atual crise da educação como crise do tempo não deve aspirar por soluções definitivas ou pré-formadas de uma vez por todas, mas sim por respostas novas para questões que se renovam e se recolocam a partir da atualidade. Arendt buscou salvar o presente da "ausência de pensamento" (thoughlessness), ou seja, da "despreocupação negligente”, da "confusão desesperada" ou da mera "repetição complacente de 'verdades' que se tornaram vazias e triviais" (Arendt, 2010, p. 6). Esse esforço busca inserir o presente em uma rearticulação histórica com o passado e o futuro, evitando que a nossa presença no tempo seja apagada pelo esquecimento e pela superficialidade. $\mathrm{O}$ empenho filosófico arendtiano almeja nos inspirar o amor ao mundo (amor mundi) e a responsabilidade para com ele, tão indispensáveis para podermos afugentar a ruína do nosso mundo. A desmontagem positiva e apropriativa da tradição não abandona o passado, pois atualiza seus fragmentos, suas possibilidades esquecidas e soterradas, suas significações obscurecidas e seus preconceitos sedimentados.

Arendt evidencia que a fratura que nosso presente provoca em nossa história não pode ser pensada por uma tradição na qual possamos nos fiar e não pode ser compreendida como concretização de alguma utopia meta-histórica. Por isso, nossa presença no tempo se tornou insegura e desamparada, reivindicando uma nova relação entre pensamento, atualidade e tempo histórico, ou seja, uma nova experiência temporal que rearticule o modo como o presente se relaciona com o passado e o futuro. Cada época espera pela construção de sua atualidade, impondo resistência e descontinuidade ao mero devir transitório e ordinário, instaurando uma brecha 
atemporal a partir de uma confrontação positiva com o seu passado e o seu futuro. Essa confrontação não pode ser concedida pela tradição porque reivindica a cada época a capacidade de criar, defender e preservar a sua presença, diante das pressões das forças temporais, impedindo que as significações, as experiências e os eventos sejam anulados, devorados e transformados em ruínas. Por isso Agamben afirma que

toda concepção da história é sempre acompanhada de certa experiência do tempo que lhe é implícita, que a condiciona e que é preciso, portanto, trazer à luz. (...) A tarefa original de uma autêntica revolução não é jamais simplesmente 'mudar o mundo', mas também e, antes de tudo, "mudar o tempo" (2005, p. 15). 


\section{REFERÊNCIAS:}

AGAMBEN, G. Infância e História: destruição da experiência e origem da história. Belo Horizonte: UFMG, 2005.

A crise infindável como instrumento de poder: uma conversa com Giorgio Agamben. Disponível em: https://blogdaboitempo.com.br/2013/07/17/a-crise-infindavel-como-instrumento-de-poder-uma-conversa-com-giorgioagamben/ Acessado em 29/02/2019.

ALMEIDA, Vanessa Sievers. Educação em Hannah Arendt: entre o mundo deserto e o amor ao mundo. São Paulo: Cortez, 2011.

ARENDT, Hannah. A crise na educação. In: Entre o passado e o futuro. Trad. Mauro W. Barbosa de Almeida. 6. ed. São Paulo: Perspectiva, 2007a.

. Que é autoridade?. In: Entre o passado e o futuro. Trad. Mauro W. Barbosa de Almeida. 6.ed. São Paulo: Perspectiva, 2007b.

. O conceito de história - antigo e moderno. In: Entre o passado e o futuro. Trad. Mauro W. Barbosa de Almeida. 6.ed. São Paulo: Perspectiva, 2007c.

Origens do totalitarismo. São Paulo: Companhia das Letras, 2004.

2010.

A Condição Humana. Trad. Roberto Raposo. Revisão Adriano Correia. Rio de Janeiro: Forense Universitária,

ASSIS CÉSAR, Maria Rit; DUARTE, André. Hannah Arendt: pensar a crise da educação no mundo contemporâneo. In: Educação e Pesquisa, São Paulo, v. 36, n.3, p. 823-837, set./dez. 2010.

BENJAMIN, W. O Narrador/Experiência e Pobreza. In: Obras Escolhidas, vol. 1. Magia e Técnica, Arte e Política. Ensaios sobre Literatura e História da Cultura. São Paulo: Brasiliense, 1987.

BERARDI, Franco. Depois do Futuro. São Paulo: Ubu Editora, 2019.

BIRULÉS, FINA. Um passado para o futuro: Autoridade e educação em Hannah Arendt. In: FONSECA DE CARVALHO e CUSTÓDIO, Crislei de Oliveira. (Orgs.). Hannah Arendt: a crise na educação e o mundo moderno. São Paulo: Intermeios, 2016.

BYUNG-CHUL HAN. O aroma do tempo. Ensaio filosófico sobre a arte da demora. Lisboa: Relógio d'Água, 2016.

DEBORD, Guy. A sociedade do espetáculo. Rio de Janeiro: Contraponto, 1997.

DETIENNE, Marcel. Comparar lo incomparable. Barcelona: Península, 2001.

HARTOG, F. Regimes de historicidade: presentismo e experiências do tempo. Belo Horizonte: Autêntica, 2014.

KOSELLECK, R. Futuro passado: contribuição à semântica dos tempos históricos. Rio de Janeiro: Contraponto, 2006.

LEOPOLDO E SILVA, F. Descontrole do tempo histórico e banalização da experiência”. I: NOVAES, Adauto. (Org.). Mutações. Rio de Janeiro: Ed. Agir, 2008.

LIPOVETSKY, G. A Era do Vazio: Ensaios Sobre o Individualismo Contemporâneo. Lisboa: Manole, 2005.

MATOS, Olgária. O mal estar na contemporaneidade: performance e tempo. In: Revista do Serviço Público, Brasília, 59 (4): 455-468, out./dez. 2008.

REVAULT D’ALLONES, Myriam. El poder de los comienzos. Ensayo sobre la autoridade. Buenos Aires: Amorrotu, 2008.

SHALINS, Marshall. Islas de historia. Barcelona: Gedisa, 1987.

VATTIMO, G. Fim da Modernidade. São Paulo: Martins Fontes, 1996. 


\section{RESUMO}

O artigo interpreta a crise da autoridade e a crise da educação, tal como diagnosticadas por Hannah Arendt, como expressões de uma crise da temporalidade e da historicidade no mundo moderno. Diferentes reflexões sobre a atual ordem do tempo apontam para a contemporaneidade como expressão de transformações sociais e tecnológicas das quais emergiu um novo regime de historicidade em que o presente se encontra cada vez mais prolongado, desconectado do passado, pobre em experiência, desprovido de direcionalidade e com o futuro cada vez mais opaco, administrado e imediato. A crise da educação seria hoje expressão do enfraquecimento da tensão entre novidade e memória provocada por esse presentismo que abole a articulação entre o passado e o futuro, transformando a cultura em mercadoria para o consumo instantâneo e voraz de adultos e jovens governados pelo ideal de felicidade momentânea e imediata.

Palavras-chave: Arendt; crise; educação; autoridade; tempo.

\section{ARENDT AND THE CRISIS OF EDUCATION AS A CRISIS OF HISTORICAL TIME}

\section{ABSTRACT}

The article interprets the crisis of authority and the crisis of education, as diagnosed by Hannah Arendt, as expressions of a crisis of temporality and historicity in the modern world. Different reflections on the current order of time point to contemporaneity as an expression of social and technological transformations from which emerged a new regime of historicity in which the present is more and more prolonged, disconnected from the past, poor in experience, devoid of directionality and with the future increasingly opaque, managed and immediate. The crisis of education would today be an expression of the weakening of the tension between novelty and memory provoked by this presentism that abolishes the articulation between the past and the future, transforming the culture into merchandise for the instantaneous and voracious consumption of adults and young people governed by the ideal of happiness momentary and immediate.

Keywords: Arendt; crisis; education; authority; time.

\section{ARENDT Y LA CRISIS DE LA EDUCACIÓN CÓMO CRISIS DEL TIEMPO HISTÓRICO}

\section{RESUMEN}

El artículo interpreta la crisis de autoridad y la crisis de la educación, tal como lo diagnosticó Hannah Arendt, como expresiones de una crisis de temporalidad e historicidad en el mundo moderno. Diferentes reflexiones sobre el orden actual del tiempo apuntan a la contemporaneidad como una expresión de las transformaciones sociales y tecnológicas de las que surgió un nuevo régimen de historicidad en el que el presente es cada vez más prolongado, desconectado del pasado, pobre en experiencia, carente de direccionalidad y con el futuro cada vez más opaco, gestionado e inmediato. La crisis de la educación es hoy una expresión del debilitamiento de la tensión entre novedad y memoria provocada por este presentismo que suprime la articulación entre el pasado y el futuro, transformando la cultura en mercadería para el consumo instantáneo y voraz de adultos y jóvenes gobernados por el ideal de la felicidade momentánea e inmediata.

Palabras clave: Arendt; crisis; educacion; autoridad; tempo.

Submetido em 30 de abril de 2019 Aprovado em 05 de agosto de 2019 